\title{
The presence of glucose increases the lethal effect of $\alpha$-chlorohydrin on ram and boar spermatozoa in vitro
}

\author{
W. C. L. Ford and Anne Harrison
}

Department of Physiology \& Biochemistry, The University, Whiteknights, Reading RG6 2AJ, U.K.

\begin{abstract}
Summary. Ram cauda epididymal spermatozoa were incubated for $10 \mathrm{~min}$ at $34^{\circ} \mathrm{C}$ with or without $1.0 \mathrm{~mm}-R S$ - $\alpha$-chlorohydrin before (1) $5 \mathrm{~mm}$-D-glucose or (2) $10 \mathrm{~mm}$-L-lactate plus $1 \mathrm{~mm}$ pyruvate or (3) $5 \mathrm{~mm}$-D-glucose plus $10 \mathrm{~mm}$-L-lactate plus $1 \mathrm{~mm}$-pyruvate or (4) no substrate was added. Without $\alpha$-chlorohydrin, the motility, the ATP concentration and the energy charge of the spermatozoa were maintained for $240 \mathrm{~min}$ by substrate combinations $1-3$ but with no added substrate (4) the motility declined after $60 \mathrm{~min}$. All the values decreased dramatically after $10 \mathrm{~min}$ in spermatozoa exposed to $\alpha$-chlorohydrin in substrate conditions 1 and 3 (glucose present) but $\alpha$-chlorohydrin had no significant effect in conditions 2 and 4 (no glucose) except after prolonged incubation. In a dose-response experiment glucose-dependent ATP dissipation began to occur with $0.025 \mathrm{mM}-R S$ - $\alpha$-chlorohydrin. A similar effect was seen in boar spermatozoa exposed to $0 \cdot 1-5.0 \mathrm{~mm}-\alpha$-chlorohydrin and $5 \mathrm{~mm}-\mathrm{D}$-glucose. With boar spermatozoa the presence of $10 \mathrm{mM}$-L-lactate and $1 \mathrm{mM}$-pyruvate as well as glucose prevented the loss of ATP.

We conclude that this concerted action of $\alpha$-chlorohydrin and glucose is probably responsible for the contraceptive action of $\alpha$-chlorohydrin and propose that it may depend on 'futile substrate cycling' in the glycolytic pathway.
\end{abstract}

\section{Introduction}

Both $\alpha$-chlorohydrin (see Jones, A.R., 1978, 1983; Lobl, 1980) and the 6-chloro-6-deoxysugars (see Ford, 1982) have a rapid and reversible antifertility action in male animals. The contraceptive effect is believed to result from the inhibition of glyceraldehyde 3-phosphate dehydrogenase (EC 1.2.1.12) in spermatozoa (Brown-Woodman, Mohri, Mohri, Suter \& White, 1978; Ford, Harrison $\&$ Waites, 1981). When $\alpha$-chlorohydrin and 6-chloro-6-deoxysugars are administered to male rats their effects on the spermatozoa are identical but only $\alpha$-chlorohydrin will inhibit glyceraldehyde 3phosphate dehydrogenase in normal spermatozoa exposed to it in vitro (Ford \& Waites, 1982). The inhibition of glyceraldehyde 3-phosphate dehydrogenase prevents the spermatozoa from obtaining energy from the metabolism of glucose or fructose and if the inhibited spermatozoa are incubated with these substrates the cells soon become immotile with a concomitant decline in ATP concentration (Brown-Woodman et al., 1978; Ford \& Harrison, 1981). However, this may not be sufficient to explain why the spermatozoa are infertile because contraceptive doses of the compounds do not impair the ability of the spermatozoa to utilize non-glycolytic substrates (Brown-Woodman et al., 1978; Ford et al., 1981) and spermatozoa from rats made infertile with 6-chloro-6-deoxyglucose remained motile with a normal ATP concentration when incubated with pyruvate plus lactate (Ford \& Harrison, 1981). A rich mixture of substrates including lactate and pyruvate is available in the female reproductive tract (Lutwak-Mann, 1962; Iritani, Gomes \& VanDemark, 1969; Brackett \& Mastroianni, 1974) together with an adequate supply of oxygen (Mastroianni \& Jones, 1965). Therefore the spermatozoa should be equally able to obtain cenergyifrom lactate and pyravate in : 49:18AM 
vivo. The presence of glucose is required for the capacitation of mouse spermatozoa in vitro although other substrates can maintain the viability of the cells which remain motile and rapidly capacitate if glucose is added subsequently (Hoppe, 1976; Fraser \& Quinn, 1981). Therefore $\alpha$-chlorohydrin might work by blocking the glucose metabolism associated with capacitation. $\alpha$-Chlorohydrin at $10 \mu \mathrm{M}$ will block the acrosome reaction of hamster spermatozoa (Dravland \& Meizel, 1981), but hamster spermatozoa will capacitate without glucose (see Rogers, 1978) whereas mice are unusually resistant to the contraceptive action of $\alpha$-chlorohydrin (Tsunoda \& Chang, 1976). It is difficult to carry out extensive metabolic experiments with rodent spermatozoa because of the comparatively small number of cells available. At the same time $\alpha$-chlorohydrin has similar effects on metabolism in spermatozoa from rams and boars and from rodents and we decided to take advantage of the large numbers of spermatozoa available from these large animals to design experiments to clarify the effect of different substrate combinations on the viability of spermatozoa treated with $\alpha$ chlorohydrin. A preliminary account of some of this work has appeared (Ford \& Harrison, 1983a).

\section{Materials and Methods}

\section{Materials}

Testes from sexually mature ram lambs were obtained from Alf Meade Ltd, The Abattoirs, Reading. The slaughtermen were asked to keep organs cool but not to chill them and we attempted to collect them as soon as possible after slaughter. The sperm rich fraction of boar semen was generously donated by the Ministry of Agriculture, Fisheries and Food, Artificial Insemination Centre, Shinfield, Reading, and was brought to the laboratory within $1 \mathrm{~h}$ of ejaculation. $\mathrm{D}-\left[\mathrm{U}-{ }^{14} \mathrm{C}\right] \mathrm{glucose}$ and $\mathrm{D}-\left[2-{ }^{3} \mathrm{H}\right]$ glucose were purchased from Amersham International p.l.c., Amersham HP7 9LL, U.K. Enzymes and biochemicals were supplied by Sigma London Chemical Co. Ltd, Poole, Dorset BH17 7NH, U.K., or by Boehringer Corpn. (London) Ltd, Lewes BN7 1LG, U.K. RS- $\alpha$-Chlorohydrin was supplied by Koch-Light Ltd, Colnbrook SL3 OBZ, U.K., and was redistilled under reduced pressure before use. Other reagents were obtained from Fisons Scientific Apparatus, Loughborough LE11 0R9, U.K.

\section{Preparation of spermatozoa}

Ram. A polyvinylchloride cannula $(0.8 \mathrm{~mm}$ o.d., $0.5 \mathrm{~mm}$ i.d.) was inserted in the vas deferens and a cut was made in the cauda epididymidis. Spermatozoa were expelled by forcing phosphatebuffered physiological saline (PBS) $\left(143 \mathrm{mM}-\mathrm{NaCl} ; 2.7 \mathrm{~mm}-\mathrm{KCl} ; 8.1 \mathrm{~mm}-\mathrm{Na}_{2} \mathrm{HPO}_{4} ; 1.5 \mathrm{~mm}-\right.$ $\mathrm{KH}_{2} \mathrm{PO}_{4} ; 0.8 \mathrm{~mm}-\mathrm{CaCl}_{2} ; 0.8 \mathrm{mM}-\mathrm{MgCl}_{2} ; 0.1 \mathrm{~mm}$-EDTA (tetrasodium salt) $; 15 \mu \mathrm{M}$-bovine serum albumin (Cohn Fraction V); $0.25 \mathrm{mM}$-penicillin G;80 $\mu \mathrm{M}$-streptomycin sulphate: Ford et al., 1981) down the cannula. The spermatozoa were dispersed in the saline and centrifuged $\left(500 \mathrm{~g}_{\mathrm{av}}, 10 \mathrm{~min}\right.$, room temperature); the pellet was washed once and the spermatozoa were suspended in PBS at a concentration of about $10^{8} \mathrm{cells} / \mathrm{ml}$.

Boar. The semen was diluted with a roughly equal volume of PBS and was centrifuged $\left(500 \mathrm{~g}_{\mathrm{av}}\right.$, $10 \mathrm{~min}$ room temperature). The pellet was washed twice and the spermatozoa were suspended in PBS at a concentration of about $10^{8}$ cells $/ \mathrm{ml}$.

The concentration of spermatozoa was determined with a haemocytometer.

\section{Experiment 1: the effect of different substrates on ram spermatozoa treated with $1.0 \mathrm{mM}-\alpha$-chlorohydrin}

Two 24-ml samples, A and B, were removed from the sperm suspension. Sample A was mixed with $1.0 \mathrm{ml} 25 \mathrm{mM}-R S$ - $\alpha$-chlorohydrin and Sample B with $1.0 \mathrm{ml}$ PBS. The two samples were incubated with shaking at $34^{\circ} \mathrm{C}$ and, after $9 \mathrm{~min}$, a $0.25-\mathrm{ml}$ sample was removed from Sample A for motility measurement. After $10 \mathrm{~min}$, a similar sample was removed from Sample B and 1.0-ml samples were taken from each flask and mixed with $0.50 \mathrm{ml} \mathrm{1.0} \mathrm{M-perchloric} \mathrm{acid.} \mathrm{At} \mathrm{the} \mathrm{same} \mathrm{time,}$ 
4.8-ml portions were mixed with $0 \cdot 20 \mathrm{ml} \mathrm{PBS}$ which contained the additions required to produce the following final concentrations: (1) no substrate, (2) $5 \mathrm{~mm}-\mathrm{D}-\left[\mathrm{U}-{ }^{14} \mathrm{C}, 2-{ }^{3} \mathrm{H}\right] \mathrm{glucose}$, (3) $10 \mathrm{mM}-\mathrm{L}$ lactate plus $1 \mathrm{~mm}$-pyruvate, (4) $5 \mathrm{~mm}$-D-[U-14 $\left.\mathrm{C}, 2-{ }^{3} \mathrm{H}\right] \mathrm{glucose}$ plus $10 \mathrm{~mm}$-L-lactate plus $1 \mathrm{~mm}$-pyruvate. The specific activity of the glucose was $0.5 \mathrm{Ci}{ }^{3} \mathrm{H} / \mathrm{mol}$ and $0.05 \mathrm{Ci}{ }^{14} \mathrm{C} / \mathrm{mol}$. Incubation continued at $34^{\circ} \mathrm{C}$ and $1.0-\mathrm{ml}$ samples were taken from all the flasks $10,30,60$ and $240 \mathrm{~min}$ after the addition of substrate and mixed with $0.50 \mathrm{ml} 1.0 \mathrm{M}$-perchloric acid. Samples for motility measurement $(0.25 \mathrm{ml})$ were removed from the $\alpha$-chlorohydrin flask with no added substrate (Group 1) after 13, 43 and $225 \mathrm{~min}$ and from the corresponding control flask (no $\alpha$-chlorohydrin) after 28,58 and $240 \mathrm{~min}$. Similar samples were taken from the other flasks at $1 \mathrm{~min}$ (Group 2), $2 \mathrm{~min}$ (Group 3) and $3 \mathrm{~min}$ (Group 4) after these samples. In the statistical analysis of the motility data, each series of samples taken from the $\alpha$-chlorohydrin-treated spermatozoa was compared to the series of control samples succeeding it, e.g. the series beginning at 13 min was compared to the control series starting at $28 \mathrm{~min}$. Since sperm motility usually declines during control incubations, this procedure will tend to underestimate the effect of treatment. The acidified samples were centrifuged and neutralized as described previously (Ford et al., 1981).

Experiment $2:$ the minimum concentration of $\alpha$-chlorohydrin needed to induce the rapid loss of ATP from ram spermatozoa after the addition of $5 \mathrm{mM}-\mathrm{D}-\mathrm{glucose}$

Portions $(5 \mathrm{ml})$ of a suspension of ram spermatozoa were incubated with $0,0.01,0.025,0.05$, 0.075 or $0.10 \mathrm{~mm}-R S-\alpha$-chlorohydrin at $34^{\circ} \mathrm{C}$ for $10 \mathrm{~min}$. Samples $(1.0 \mathrm{ml})$ were removed from each flask and mixed with $0.50 \mathrm{ml} 1.0 \mathrm{M}$-perchloric acid and $5 \mathrm{mM}-\mathrm{D}$-glucose was added to the flasks. Incubation continued at $34^{\circ} \mathrm{C}$ and $1.0-\mathrm{ml}$ samples were taken 10,30 and 60 min later.

\section{Experiment 3: the effect of glucose on the loss of $A T P^{\prime}$ in boar spermatozoa treated with $\alpha$-chlorohydrin}

Five 6-ml portions of sperm suspension were incubated at $34^{\circ} \mathrm{C}$ for $10 \mathrm{~min}$ with $0,0 \cdot 1,0 \cdot 05,1 \cdot 0$, 2.0 or $5.0 \mathrm{~mm}-R S$ - $\alpha$-chlorohydrin. A $0.5-\mathrm{ml} \mathrm{sample} \mathrm{was} \mathrm{removed} \mathrm{from} \mathrm{each} \mathrm{and} \mathrm{mixed} \mathrm{with} 1.0 \mathrm{ml}$ $0.5 \mathrm{M}$-perchloric acid and then $1.7-\mathrm{ml}$ portions were taken and mixed with substrate or PBS to give (1) no substrate, (2) $5 \mathrm{mM}$-D-glucose, (3) $5 \mathrm{mM}$-D-glucose plus $10 \mathrm{~mm}$-L-lactate plus $1 \mathrm{~mm}$-pyruvate in a total volume of $2.0 \mathrm{ml}$. Incubation continued at $34^{\circ} \mathrm{C}$ and $0.5-\mathrm{ml}$ samples were removed from all the flasks 15,30 and $60 \mathrm{~min}$ after the addition of substrate.

\section{The measurement of the motility of the spermatozoa}

Motility was measured by a turbidimetric procedure based on that described by Sokoloski, Blasco, Storey \& Wolf (1977). A length of polyvinylchloride cannula tubing ( $2.0 \mathrm{~mm} 0 . \mathrm{d} ., 1.0 \mathrm{~mm}$ i.d.) was cemented in the corner of a plastic disposable 3-ml cuvette so that the lower end was about $1 \mathrm{~mm}$ above the floor of the cuvette whilst the upper end stood proud of the top of the cuvette by about $1 \mathrm{~mm}$. PBS $(1.8 \mathrm{ml})$ was added to the cuvette which was placed in a Gilford Model 250 spectrophotometer maintained at $34^{\circ} \mathrm{C}$ by thermostat and the absorbance at $500 \mathrm{~nm}(A 0)$ was recorded. A Gilson 'Minipuls Il' peristaltic pump was adjusted to deliver $1 \mathrm{ml} / \mathrm{min}$ and was attached to a polyvinylchloride cannula which ended in a length of 21 -gauge stainless-steel tubing and was sufficient to contain $0.3 \mathrm{ml}$. Sperm suspension was taken up into the cannula by reversing the pump for $18 \mathrm{sec}$, the stainless-steel tube was inserted in the plastic guide tube glued to the cuvette and the pump was run forwards for $15 \mathrm{sec}$ to form a layer of $0.25 \mathrm{ml}$ sperm suspension on the floor of the cuvette. Spermatozoa were allowed to swim up into the buffer for $10 \mathrm{~min}$ (preliminary experiments indicated that all the motile spermatozoa left the basal layer in this period) and the absorbance $(A 1)$ was measured. The contents of the cuvette were now stirred to bring all the spermatozoa into the suspension and the absorbance was measured again $(A 2)$. The percentage of progressively motile spermatozoa (or the motility index) was taken to be $(A 1-A 0) \times 100 /(A 2-A 0)$. The spermato- 
zoa would not swim into the top millimeter or so of the buffer and very motile samples sometimes gave results in excess of $100 \%$.

\section{Assay procedures}

ATP, ADP, AMP, lactate and pyruvate were measured as described previously (Ford et al., 1981 ; Ford \& Harrison, 1981). Tritiated water was measured after subliming it from a sample of the neutralized perchloric acid extract frozen in the upper compartment of a Thunberg tube. No corrections were applied for isotope discrimination effects.

\section{Statistical evaluation of results}

The effects of treatments and substrates were analysed by a multifactorial analysis of variance and differences between individual treatments were assessed by a $t$ test using the standard errors of difference of the means. The computations were done with a computer program 'GENSTAT' provided by the Department of Applied Statistics, University of Reading. The effect of $\alpha$-chlorohydrin in the preincubation period before the addition of substrate was tested in a two-way analysis of variance.

\section{Results}

Experiment 1: the effects of different substrates on ram spermatozoa treated with $1.0 \mathrm{mM}-\mathrm{RS}-\alpha-$ chlorohydrin

Motility. The spermatozoa in the initial suspension had a motility index of $65 \pm 11.9$ (mean \pm s.e.m., $n=4)$. This increased significantly $(P<0.05)$ to $81 \pm 10.0$ after the 10 -min preincubation with $1 \mathrm{~mm}-\alpha$-chlorohydrin but remained essentially unchanged $(63 \pm 4 \cdot 8)$ in the controls. With no added substrate the control spermatozoa maintained their motility for $60 \mathrm{~min}$ but after $240 \mathrm{~min}$ the motility index had declined to $27 \pm 2 \cdot 8$ (Text-fig. 1). When substrates were added the spermatozoa

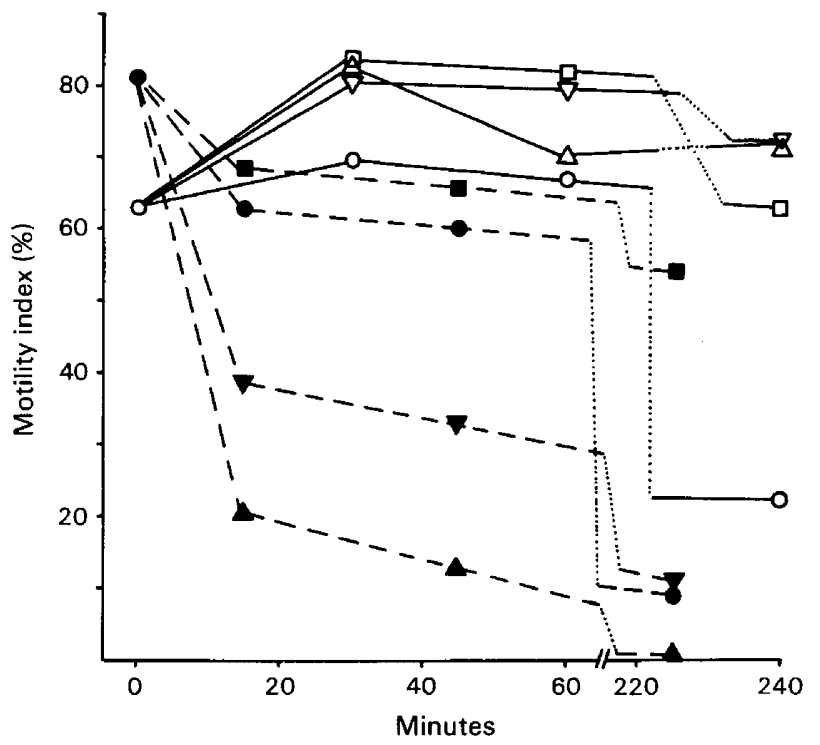

Text-fig. 1. The motility index (for definition see text) of ram cauda epididymal spermatozoa washed and suspended in PBS and preincubated for $10 \mathrm{~min}$ at $34^{\circ} \mathrm{C}$ with $1 \mathrm{mM}-R S$ - $\alpha$-chlorohydrin $(O, \Delta, \square, \nabla)$ or with no additions $(O, \triangle, \square, \nabla)$ before the substrates were added and the incubation continued for a further $4 \mathrm{~h}$. No added substrate $(O, O) ; 5$ mM-D-glucose $(\triangle$, $\Delta) ; 10 \mathrm{~mm}$-L-lactate plus $1 \mathrm{~mm}$-pyruvate $(\square, \square) ; 5 \mathrm{~mm}$-glucose plus $10 \mathrm{~mm}$-L-lactate plus $1 \mathrm{mM}$ pyruvate $(\nabla, \nabla)$. Values are means of 4 experiments ded from Bioscientifica.com at 04/26/2023 02:49:18AM 
were more motile and they maintained their activity for $240 \mathrm{~min}$ (Text-fig. 1). The analysis of variance showed that the effect of substrate overall was significant $(P<0.001)$ but the differences at 30 or 60 min taken by themselves were of doubtful significance $(0.05<P<0.10)$. When no substrate was added to spermatozoa treated with $1.0 \mathrm{~mm}-\alpha$-chlorohydrin, the motility index was $60 \pm 9 \cdot 8$ after $45 \mathrm{~min}$ but only $9 \pm 3.8$ after $225 \mathrm{~min}$ and when $10 \mathrm{~mm}$-L-lactate plus $1 \mathrm{~mm}$-pyruvate was added the motility index was $66 \pm 6.8$ after $45 \mathrm{~min}$ and $54 \pm 3.3$ after $225 \mathrm{~min}$ (Text-fig. 1). In these 2 conditions the motility at 15 or $45 \mathrm{~min}$ of the spermatozoa exposed to $\alpha$-chlorohydrin was not significantly different from that of control spermatozoa measured 15 min later, but when the $225 / 240 \mathrm{~min}$ data were included a significant deleterious effect $\alpha$-chlorohydrin was revealed ( $P<0.05$, no substrate; $P<0.01$, lactate + pyruvate). When $5.0 \mathrm{~mm}$-D-glucose was added the motility index declined to $20 \pm 2.8$ after $15 \mathrm{~min}$ and with $5.0 \mathrm{mM}$-D-glucose plus $10 \mathrm{mM}-\mathrm{L}$-lactate plus 1 mM-pyruvate the motility index was $39 \pm 4.2$ at this time (Text-fig. 1). The interaction between $\alpha$-chlorohydrin and glucose responsible for this decline produced a highly significant $(P<0.001)$ interaction sum of squares between $\alpha$-chlorohydrin and substrate in the analysis of variance.

Adenine nucleotide concentrations. The concentrations of ATP, ADP and AMP in control spermatozoa changed only slightly during incubation for $240 \mathrm{~min}$ under any of the substrate conditions and the only significant difference $(P<0.01)$ between the groups was a higher concentration of ADP when no substrate was added. The energy charge (Atkinson \& Walton, 1967) remained about 0.80 throughout (Text-fig. 2). The nature of the substrate provided had a large effect in the spermatozoa treated with $1 \mathrm{~mm}-\alpha$-chlorohydrin. With $10 \mathrm{~mm}$-lactate plus $1 \mathrm{~mm}$-pyruvate the adenine nucleotide concentrations remained similar to those in control spermatozoa throughout the experiment. The same was true with no added substrate for the first $60 \mathrm{~min}$ but then the concentration of ATP in the treated spermatozoa fell markedly by $240 \mathrm{~min}(P<0.01)$ with a concomitant increase in AMP $(P<0.001)$ and a decrease in the energy charge (Text-fig. 2$)$. By contrast, in the incubations with $5 \mathrm{mM}$-D-glucose or with $5 \mathrm{~mm}$-D-glucose plus $10 \mathrm{~mm}-\mathrm{L}$-lactate plus $1 \mathrm{~mm}$ - pyruvate, the ATP concentration fell by about $60 \%$ after only $10 \mathrm{~min}$ and remained low for the remainder of the incubation. There was a corresponding increase in the concentrations of ADP and of AMP so that the total adenine nucleotide concentration remained constant for $60 \mathrm{~min}$ although it did decline slightly after $240 \mathrm{~min}$. The energy charge declined dramatically in concert with the ATP concentration (Text-fig. 2). The interaction between $\alpha$-chlorohydrin treatment and the effect of substrate was significant $(P<0.001)$.

Metabolism of the substrates. No lactate was produced in the absence of added substrate. Control spermatozoa produced about $1 \mu \mathrm{mol}$ lactate $/ 10^{8}$ spermatozoa from $5 \mathrm{~mm}$-glucose in the first $60 \mathrm{~min}$ of the incubation and had produced about $3 \mu \mathrm{mol}$ lactate $/ 10^{8}$ spermatozoa after $4 \mathrm{~h}$. In the presence of $5 \mathrm{mM}$-D-glucose plus $10 \mathrm{mM}$-L-lactate plus $1 \mathrm{~mm}$ pyruvate about $1.8 \mu \mathrm{mol}$ of additional lactate $/ 10^{8}$ spermatozoa was formed in the first $60 \mathrm{~min}$ but only a further $0.6 \mu \mathrm{mol}$ lactate $/ 10^{8}$ spermatozoa was produced in the next $3 \mathrm{~h}$. The production of lactate was nearly completely inhibited by $\alpha$-chlorohydrin treatment (Text-fig. 3a). In the incubations with $10 \mathrm{~mm}$-L-lactate plus $1 \mathrm{~mm}$-pyruvate the concentration of lactate did not change significantly during the first $60 \mathrm{~min}$ of incubation and about $1 \mu \mathrm{mol}$ lactate $/ 10^{8}$ spermatozoa was consumed in the subsequent $3 \mathrm{~h}$ by both control and $\alpha$-chlorohydrin-treated spermatozoa, but $\alpha$-chlorohydrin-treated spermatozoa incubated with glucose, lactate and pyruvate consumed no lactate (Text-fig. 3a). When pyruvate was present in the substrate mixture it was consumed rapidly and this was not affected by $\alpha$-chlorohydrin (Text-fig. $3 b$ ). The release of ${ }^{3} \mathrm{HOH}$ from $\left[2-{ }^{3} \mathrm{H}\right]$ glucose was only sufficient to account for $60-70 \%$ of the lactate production of control spermatozoa and it was slightly decreased when the substrate mixture contained lactate and pyruvate as well as glucose. The apparent shortfall in ${ }^{3} \mathrm{HOH}$ release can probably be explained by tritium retention in fructose 6-phosphate and isotope discrimination (see Katz \& Rognstad, 1976). ${ }^{3} \mathrm{HOH}$ release after the first $10 \mathrm{~min}$ of the incubation was markedly but not completely inhibited by $\alpha$-chlorohydrin and with $\alpha$-chlorohydrin treatment the presence of pyruvate and lactate enhanced ${ }^{3} \mathrm{HOH}$ release in the later stages of the incubation (Text-fig. $3 \mathrm{c}$ ). 

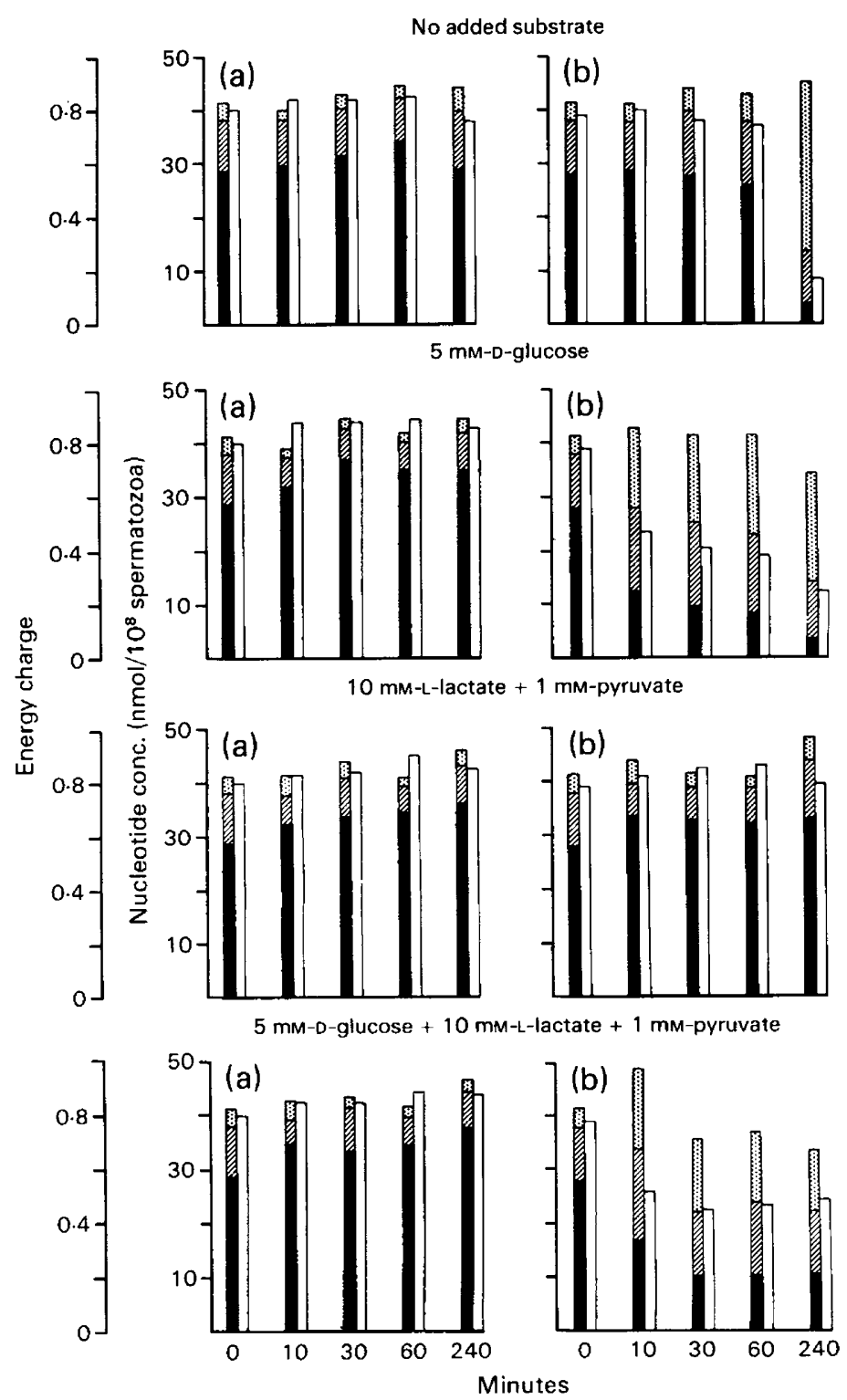

Text-fig. 2. The concentrations of ATP ( $\square$ ), ADP (ש), and AMP (圈) and the energy charge $\left(\mathrm{ATP}+\frac{1}{2} \mathrm{ADP}\right) /(\mathrm{ATP}+\mathrm{ADP}+\mathrm{AMP})(\square)$ in the spermatozoa described in Text-fig. 1. (a) Controls, (b) $1 \mathrm{mM}-R S$ - $\alpha$-chlorohydrin. Values are means of 3 experiments.

\section{Experiment 2: the effect of $\alpha$-chlorohydrin concentration}

There was no effect on lactate production from $5 \mathrm{mM}$-D-glucose by the spermatozoa or on the concentration of ATP in the cells treated by $0.01 \mathrm{mM}-\alpha$-chlorohydrin, but $0.025 \mathrm{mM}-R S-\alpha-$ chlorohydrin caused a small but significant $(P<0 \cdot 01)$ inhibition of lactate production in the final 30 min of the incubation and a small fall in ATP concentration compared to control spermatozoa $(P<0.01)$. The intensity of both of these effects increased with higher $\alpha$-chlorohydrin concentration and lactate production after the first 10 -min incubation was completely inhibited by 0.075 or by $0 \cdot 10 \mathrm{~mm}-R S-\alpha-$ chlorohydrin (Text-fig. 4 ). 

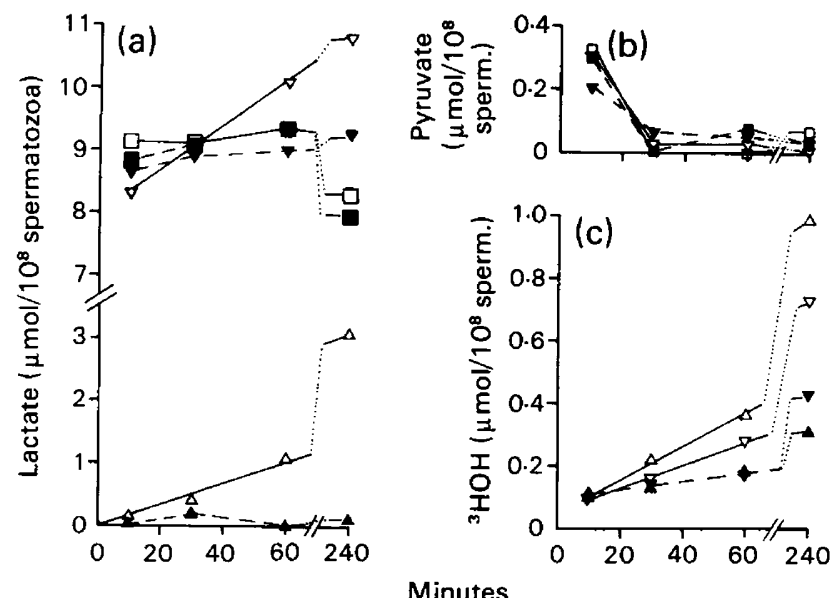

Text-fig. 3. The concentrations of (a) lactate and (b) pyruvate, and (c) the release of ${ }^{3} \mathrm{HOH}$ from $\mathrm{D}-\left[2-{ }^{3} \mathrm{H}\right]$ glucose in the experiment described in Text-fig. $1 . \square, \boldsymbol{\nabla}, \Delta: 1 \mathrm{mM}-R S$ - $\alpha$-chlorohydrin; $\square, \nabla, \triangle$ : controls; $\triangle, \Delta: 5 \mathrm{~mm}$-D-glucose; $\square, \square: 10 \mathrm{mm-L-lactate} \mathrm{plus} 1 \mathrm{~mm}$-pyruvate; $\nabla, \nabla: 5 \mathrm{~mm}$-D-glucose plus $10 \mathrm{~mm}$-L-lactate plus $1 \mathrm{~mm}$-pyruvate. Values are means of 3 experiments.

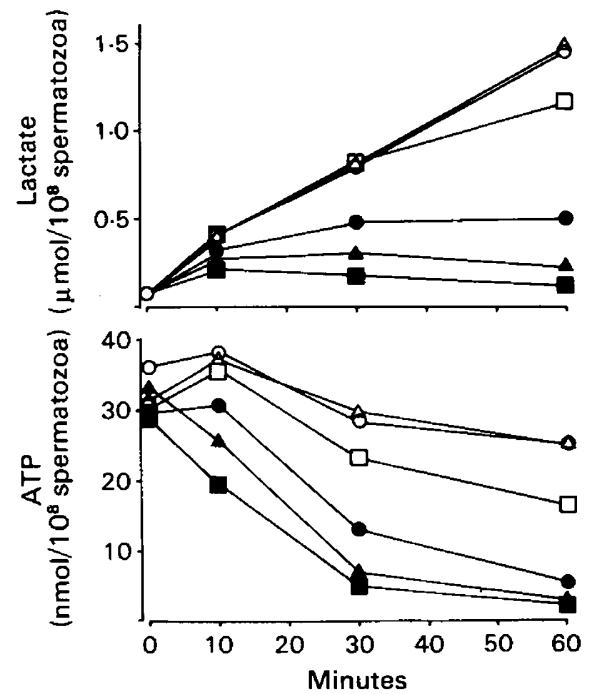

Text-fig. 4. The concentrations of lactate and ATP in ram epididymal spermatozoa, washed and suspended in PBS buffer and incubated for $10 \mathrm{~min}$ at $34^{\circ} \mathrm{C}$ with $0(\mathrm{O}), 0.01(\triangle), 0.025(\square)$, $0.05(\mathbf{O}), 0.75(\Lambda)$ or $0.10(\square) \mathrm{mM}-R S$ - $\alpha$-chlorohydrin before $5 \mathrm{~mm}$-D-glucose was added at $0 \mathrm{~min}$ on the time-scale shown. Values are means of 3 experiments.

\section{Experiment 3: the effect of $\alpha$-chlorohydrin and glucose on boar spermatozoa}

The initial condition of the spermatozoa was very variable and all the results have been expressed as a percentage of the ATP concentration at zero time which was $18.9 \pm 0.58,9.9 \pm 0.42$ and $8.4 \pm 0.33 \mathrm{nmol} / 10^{8}$ spermatozoa in the 3 replicates respectively. In the absence of added substrate the ATP concentration in the spermatozoa declined by about $40 \%$ during incubation for $1 \mathrm{~h}$ 

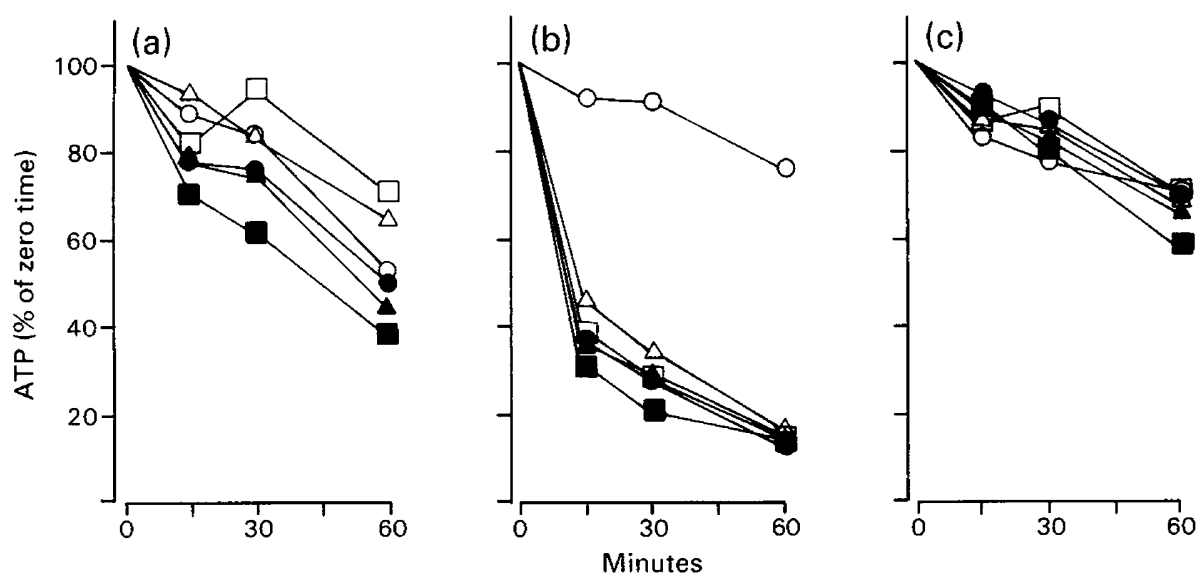

Text-fig. 5. The concentration of ATP as a percentage of its initial value in boar ejaculated spermatozoa washed and suspended in PBS buffer and preincubated for $10 \mathrm{~min}$ at $34^{\circ} \mathrm{C}$ with 0 (O), $0 \cdot 1(\triangle), 0.5(\square), 1 \cdot 0(\bigcirc), 2 \cdot 0(\Delta)$ or $5 \cdot 0(\mathrm{D}) \mathrm{mM}-R S$ - $\alpha$-chlorohydrin before the addition of no further substrate (a) or $5 \mathrm{mM}$-D-glucose (b) or $5 \mathrm{mM}$-D-glucose plus $10 \mathrm{~mm}$-L-lactate plus 1 mM-pyruvate (c). Values are means of 3 experiments.

but this decline was only slightly accelerated by $5 \mathrm{mM}-R S-\alpha$-chlorohydrin. When $5 \mathrm{mM}$-D-glucose was added the ATP concentration in spermatozoa with no $\alpha$-chlorohydrin declined more slowly and fell by only $25 \%$ after $1 \mathrm{~h}$ incubation, but all the concentrations of $\alpha$-chlorohydrin produced a rapid loss of ATP in the first $15 \mathrm{~min}$. When $5 \mathrm{~mm}$-D-glucose plus $10 \mathrm{~mm}-\mathrm{L}$-lactate plus $1 \mathrm{~mm}$ pyruvate was present, $\alpha$-chlorohydrin had no effect on the ATP concentration which declined by about $30 \%$ during the incubation (Text-fig. 5).

\section{Discussion}

These data demonstrate that the addition of $5 \mathrm{mM}$-D-glucose increases the spermicidal effect of $\alpha$-chlorohydrin to a dramatic extent. In the absence of glucose, the motility and ATP concentration of spermatozoa exposed to $\alpha$-chlorohydrin was little different from the controls except after quite extended periods of incubation, but when $5 \mathrm{~mm}$-glucose was present these values declined markedly after only $10 \mathrm{~min}$. This effect of glucose was blocked by $10 \mathrm{~mm}$-L-lactate plus $1 \mathrm{~mm}$-pyruvate in boar spermatozoa but not in ram spermatozoa.

If the inhibition of the glycolytic pathway by $\alpha$-chlorohydrin simply blocked glucose metabolism so that the spermatozoa were unable to obtain energy from it, then $\alpha$-chlorohydrintreated spermatozoa with $5 \mathrm{~mm}$-D-glucose would be equivalent to control spermatozoa with no substrate and $\alpha$-chlorohydrin-treated spermatozoa with $5 \mathrm{~mm}$-D-glucose plus $10 \mathrm{~mm}$-lactate plus $1 \mathrm{~mm}$ pyruvate would be equivalent to control spermatozoa with $10 \mathrm{mM}$-L-lactate plus $1 \mathrm{~mm}$-pyruvate. Since this was not the case, the actions of $\alpha$-chlorohydrin and glucose must combine together to produce an unknown but greatly deleterious effect on the spermatozoa. One possibility is that a high rate of 'ATP dissipation' could be set up through 'futile substrate cycling' (see Katz \& Rognstad, 1976) in the glycolytic pathway. The low flux through the pathway combined with the high concentration of some glycolytic intermediates (Brown-Woodman et al., 1978; see Ford, 1982) in spermatozoa incubated with glucose or fructose and $\alpha$-chlorohydrin would favour a high rate of 'futile cycling' in bull spermatozoa (Hammerstedt \& Lardy, 1983). This speculation is supported by the observation that the release of ${ }^{3} \mathrm{HOH}$ from $\mathrm{D}-\left[2-{ }^{3} \mathrm{H}\right]$ glucose was inhibited less completely than the production of lactate (Text-fig. 3). This would be expected if there was cycling between glucose 
and glucose 6-phosphate (which is in rapid equilibrium with fructose 6-phosphate) through hexokinase and an enzyme with glucose 6-phosphatase activity. Glucose 6-phosphatase and fructose 1,6-bisphosphatase activity are both present in ram spermatozoa (W. C. L. Ford \& A. Harrison, unpublished observations).

The glucose-induced ATP loss can occur with low $\alpha$-chlorohydrin concentrations $(0 \cdot 01-0 \cdot 025$ $\mathrm{mM}$ ) and it is very probable that it is involved in the contraceptive action of $\alpha$-chlorohydrin in vivo. Fructose will also precipitate a rapid loss of ATP in $\alpha$-chlorohydrin treated spermatozoa (W. C. L. Ford \& A. Harrison, unpublished observations). Glyceraldehyde 3-phosphate dehydrogenase in spermatozoa from animals treated with 6-chloro-6-deoxysugars or with $\alpha$-chlorohydrin will be inhibited as they pass through the cauda epididymidis (Ford \& Harrison, 1983b) but this will have little effect on the motility of or ATP concentration in the spermatozoa because of the very low concentration of glucose or of fructose in the duct (Jones, R., 1978). However, upon ejaculation the spermatozoa are exposed to a high concentration of fructose in seminal plasma and this will quickly result in a decline of the ATP concentration to an extent where the viability of the cells cannot be maintained. This hypothesis is supported by observations on spermatozoa from the cauda epididymidis of rats treated with 6-chloro-6-deoxyglucose. The spermatozoa were as motile as those of the controls immediately after collection but soon became immotile in the presence of glucose although they maintained their activity in the presence of pyruvate plus lactate (Ford \& Harrison, 1981).

Financial support was provided by the MRC (Grant No. G7909550SB).

\section{References}

Atkinson, D.E. \& Walton, G.M. (1967) Adenosine triphosphate conservation in metabolic regulation. $J$. biol. Chem. 242, 3239-3241.

Brackett, B.G. \& Mastroianni, L., Jr (1974) Composition of oviducal fluid. In The Oviduct and its Functions, pp. 133-159. Eds A. D. Johnson \& C. W. Foley. Academic Press, New York.

Brown-Woodman, P.D.C., Mohri, H., Mohri, T., Suter, D. \& White, I.G. (1978) Mode of action of $\alpha$ chlorohydrin as an antifertility agent. Biochem. $J$. 170, 23-37.

Dravland, E. \& Meizel, S. (1981) Stimulation of hamster sperm capacitation and acrosome reaction in vitro by glucose and lactate and inhibition by the glycolytic inhibitor $\alpha$-chlorohydrin. Gamete Res. 4, 515-523.

Ford, W.C.L. (1982) The mode of action of 6-chloro-6deoxysugars as antifertility agents in the male. In Progress Towards a Male Contraceptive, pp. 159-184. Eds S. L. Jeffcoate \& M. Sandler. John Wiley, Chichester.

Ford, W.C.L. \& Harrison, A. (1981) The effect of 6chloro-6-deoxysugars on adenine nucleotide concentrations in and motility of rat spermatozoa. $J$. Reprod. Fert. 63, 75-79.

Ford, W.C.L. \& Harrison, A. (1983a) The effect of different substrate combinations on the survival of ram cauda epididymal spermatozoa exposed to $1 \cdot 0$ mM- $R S$ - $\alpha$-chlorohydrin. In The Sperm Cell, pp. 63-66. Ed. J. Andre. Martinus Nijhoff, The Hague.

Ford, W.C.L. \& Harrison, A. (1983b) The activity of glyceraldehyde 3-phosphate dehydrogenase in spermatozoa from different regions of the epididymis in laboratory rodents treated with $\alpha$-chlorohydrin or 6-chloro-deoxyglucose. J. Reprod. Fert. 69, 147-156.
Ford, W.C.L. \& Waites, G.M.H. (1982) Activities of 6chloro-6-deoxysugars and $(S) \alpha$-chlorohydrin in producing spermatocoeles in rats and paralysis in mice and in inhibiting glucose metabolism in bull spermatozoa in vitro. J. Reprod. Fert. 65, 177183.

Ford, W.C.L., Harrison, A. \& Waites, G.M.H. (1981) Effects of 6-chloro-6-deoxysugars on glucose oxidation in rat spermatozoa. J. Reprod. Fert. 63, 6773.

Fraser, L.R. \& Quinn, P.J. (1981) A glycolytic product is obligatory for initiation of the sperm acrosome reaction and whiplash motility required for fertilization in the mouse. J. Reprod. Fert. 61, 2535.

Hammerstedt, R.H. \& Lardy, H.A. (1983) The effect of substrate cycling on the ATP yield of sperm glycolysis. J. biol. Chem. 258, 8759-8768.

Hoppe, P.C. (1976) Glucose requirement for mouse sperm capacitation in vitro. Biol. Reprod. 15, 39-45.

Iritani, A., Gomes, W.R. \& VanDemark, N.L. (1969) Secretion rates and chemical composition of oviduct and uterine fluids in ewes. Biol. Reprod. 1, 72-76.

Jones, A.R. (1978) The antifertility actions of $\alpha$ chlorohydrin in the male. Life Sci. 23, 1625-1646.

Jones, A.R. (1983) Antifertility actions of $\alpha$-chlorohydrin in the male. Aust. J. biol. Sci. 36, 333-350.

Jones, R. (1978) Comparative biochemistry of mammalian epididymal plasma. Comp. Biochem. Physiol. 61, 365-370.

Katz, J. \& Rognstad, R. (1976) Futile cycles in the metabolism of glucose. Curr. Topics Cell Regul. 10, 238-289. 
Lob, T.J. (1980) $\alpha$-Chlorohydrin: Review of a model post-testicular antifertility agent. In Regulation of Male Fertility, pp. 109-122. Eds G. R. Cunningham, W. B. Schill \& E. S. E. Hafez. Martinus Nijhoff, The Hague.

Lutwak-Mann, C. (1962) Some properties of uterine and cervical fluids in the rabbit. Biochim. Biophys. Acta 58, 637-639.

Mastroianni, L., Jr \& Jones, R. (1965) Oxygen tension within the rabbit fallopian tube. J. Reprod. Fert. 9, 99-102.
Rogers, B. J. (1978) Mammalian sperm capacitation and fertilization in vitro: a critique of methodology. Gamete Res. 1, 165-223.

Sokoloski, J. E., Blasco, L., Storey, B.T. \& Wolf, D.P. (1977) Turbidimetric analysis of human sperm motility. Fert. Steril. 28, 1337-1341.

Tsunoda, Y. \& Chang, M.C. (1976) Fertilizing ability in vivo and in vitro of spermatozoa of rats and mice treated with $\alpha$-chlorohydrin. J. Reprod. Fert. 46, 401406.

Received 11 May 1984 